\title{
'La internacional del espíritu': la cultura antifascista y las redes de solidaridad intelectual en la Argentina de los años treinta ${ }^{1}$
}

\author{
RiCARDO PASOLINI \\ (IEHS-CONICET)
}

\section{Introducción}

El antifascismo como problema ha estado presente en la historiografía francesa e italiana desde larga data, en virtud del peso histórico que habían alcanzado las fuerzas políticas o las identidades políticas que participaron en el proceso de resistencia al nazismo en Europa (Droz: 1985). Así, todo un conjunto de investigaciones y relevamientos biográficos se desarrollaron desde la finalización de la Segunda Guerra Mundial en parte para establecer las causas del fenómeno de los regímenes autoritarios que habían padecido, y también para otorgar a las fuerzas que resultaron triunfantes un carnet de identidad política que establecía con claridad el papel que los partidos comunista y socialista, o los grupos políticos e intelectuales como Giustizia e Libertad (GL), habían jugado en el restablecimiento de las instituciones republicanas (VV. AA. 1963). De allí que esta historiografía -sobre todo en Italia donde es muy evidente el peso de las fuerzas antifascistas en la constitución del sistema político de dopo guerra-, esté fuertemente teñida del debate político reciente. Es decir, la discusión sobre el antifascismo en Italia se vuelve un espacio de fuertes pugnas ideológicas, en la medida en que diferentes grupos políticos, y a pesar de las fracturas y las nuevas alianzas de partidos de izquierda como el ex Partido Comunista Italiano, siguen construyendo sus identidades en función de la dicotomía que dominó la cultura política de entreguerras, como si ella -más allá de su valor instrumental- se volviera un abanico ideológico que impone límites a la variabilidad de las identidades, de modo tal que hoy se reelaboran a partir de las nociones de centro destra y centro sinistra. ${ }^{2}$ Así todo, una serie de trabajos recientes, ha recolocado el problema del antifascismo desde un

\footnotetext{
1 Una versión acotada de este artículo ha sido publicada en: Pasolini (2001: 171-1939).

2 Ver el debate generado por el estudio del historiador d'Orsi (2000: 23).
} 
lugar historiográfico que pretende escapar de elaboraciones a partir de mitos, para establecer el lugar de los actores del antifascismo más como hombres y mujeres de su tiempo, que como precursores más o menos esclarecidos respecto del futuro político italiano (Rapone 1999).

Por su parte, en Francia un nuevo interés sobre el antifascismo se ha desarrollado recientemente como respuesta al polémico libro de François Furet sobre la idea comunista en la Europa del siglo XX, en donde el autor plantea básicamente que el fenómeno político del antifascismo fue parte constitutiva de la estrategia de alianza de clases promovida por el Séptimo Congreso de la Internacional Comunista, a mediados de 1935, y que respondió casi en exclusividad como un arma de guerra al servicio de Moscú. Más allá de la sutileza argumental del ensayo de Furet (1995), la imagen del proceso que describe resulta en algún sentido "orwelliana", en la medida en que la URSS aparece como una exitosa maquinaria de disciplina no sólo interna, sino también externa, a veces con una marcada ingerencia en los temas de política nacional del resto de los países europeos.

Para otro sector historiográfico francés, este libro ha sido visto como un ejemplo representativo de una importante corriente que propone una relectura global de la historia del siglo xx, y en donde el comunismo aparece como el mal mayor del siglo, y el antifascismo como un producto instrumental que en su base se proponía el derrumbe de la democracia liberal. La respuesta ha sido, por un lado, poner en debate la experiencia del antifascismo observando las inevitables relaciones entre antifascismo y comunismo, pero indicando también el peso de las otras experiencias antifascistas que nada tuvieron que ver desde el origen con la política de los partidos comunistas. Desde esta perspectiva, el antifascismo se entiende como un conjunto de experiencias culturales y políticas particulares, que pudo constituirse durante el periodo de entreguerras en una potente fuerza de resistencia -en algunos casos en el interior de los países fascistas- alcanzando diversas expresiones organizativas apelando a una solidaridad internacional de nuevo orden respecto del antiguo internacionalismo obrero, cuyo ejemplo más espectacular lo expresan las Brigadas Internacionales en España y los movimientos intelectuales de organización supranacional, pero que en otra dimensión se tradujeron en la mise en scène de los problemas de política interna de los países afectados, en la medida en que la amenaza de un fascismo real o imaginado, interpeló a las tradiciones políticas preexistentes sobre su proyección de futuro. De este modo, el antifascismo se transformó en salvaguarda de la tradición liberal-democrática (Wolikow y Bleton-Ruget 1998). Por otra parte, se ha cuestionado la idea misma de un sistema comunista mundial, para establecer el principio de la diversidad de los comunismos, desde sus particularidades nacionales y temporales hasta su composición social interna (rol de las mujeres, los intelectuales, la juventud, etc.) (Dreyfus et al. 2000). 
Así todo, en el marco de los estudios sobre el papel de la intelectualidad francesa durante el siglo Xx, el antifascismo ha estado presente aunque como objeto no exclusivo de estudio en importantes trabajos recientes. ${ }^{3}$

Esta diversidad de perspectivas e investigaciones contrasta fuertemente con el escaso interés que hasta el momento ha desarrollado la historiografía argentina respecto del problema del antifascismo. Sólo se cuenta con una serie de artículos sobre diversos aspectos del antifascismo y una tesis doctoral sobre la relación entre antifascismo e identidad comunista, más algunos estudios que han retomado la historia del Partido Comunista Argentino (PCA) desde perspectivas novedosas. ${ }^{4}$ Pero esta carencia historiográfica contrasta aún más con el peso del fenómeno en los documentos de época. En efecto, las expresiones antifascistas estaban presentes en Argentina al menos desde el advenimiento del fascismo en Italia. Dada la importante composición de extranjeros en partidos políticos como el socialista y el comunista argentinos, y el flujo ahora identificable de los exiliados políticos en el componente inmigratorio, desde mediados de la década de 1920 es posible advertir un importante movimiento antifascista de origen italiano, que a partir del asesinato de Matteotti involucra también a los partidos de la izquierda argentina del momento. De este modo, se constituyen varias organizaciones activas como la Unione Antifascista Italiana, un organismo al que adherirán el Círcolo Giacomo Matteotti, la Sezione Socialista Italiana, el Gruppo Comunista, el Centro Repubblicano Italiano, la Unione Proletaria Italiana Reduci di Guerra y los grupos anarquistas (Fanesi 1994: 39). También, en junio de 1927, se instala en la sede partidaria de la Casa del Pueblo del Partido Socialista Argentino, un busto de Matteotti esculpido clandestinamente en Italia, y se organiza un acto conjunto de las asociaciones antifascistas, y de las dos líneas del socialismo italiano que habían sido acogidas en el seno del Partido Socialista Argentino: la reformista y la maximalista, más allá de que no se aceptaran grupos idiomáticos, pues la política de integración del socialismo argentino promovía la naturalización de los inmigrantes. ${ }^{5}$ De allí en más, los lazos entre el socialismo local y el de origen étnico no dejarán de hacerse efectivos, aunque desde el socialismo argentino se criticará la escasa voluntad de sus pares italianos de ayudar a constituir un verdadero movimiento político y sindical en el país.

Por otra parte, el PCA -a partir de una organización interna que reconocía secciones idiomáticas y que para 1928 representaban el 54\% de los afiliados de Capi-

3 Por ejemplo, Winock (1999: 298 y ss.) y Sirinelli (1996: 132 y ss.).

4 Cane (1997: 443-482), Bisso (2001: 85-113), Grillo (2001: 171-199), Pasolini (2004) y

Camarero (2003)

5 Para las diferentes líneas del Partido Socialista Argentino, Leiva (1983: 554 y ss.). 
tal Federal ${ }^{6}$ - también incorporará la temática antifascista desde órganos de prensa como L'Antifascista e Il Lavoratore, y tendrá la hegemonía desde 1927 de la Alleanza Antifascista Argentina, un organismo que tomando el modelo de la Concentrazione Antifascista de París, agrupaba a los diferentes partidos políticos italianos en el exilio, hasta el abandono de sus filas por parte de los republicanos. En rigor, la experiencia del antifascismo italiano en Argentina, aquel de las organizaciones, se caracteriza por las marcadas diferencias ideológicas de sus componentes que llevaron a innumerables luchas intestinas entre republicanos, socialistas, comunistas y anarquistas, y por ende, a cierta esterilidad política (Nascimbene 1990: 140-142). En algún sentido, sólo en las asociaciones de socorros mutuos (y en un ejemplo de prensa periódica como L'Italia del Popolo) predominó un antifascismo afectivo que se apoyaba en el ideal político de la tradición "mazziniana", y que se articuló en modo favorable con la tradición liberal argentina.

Es decir, el antifascismo está presente desde mediados de los años 20 con un fuerte componente étnico en su constitución. Este componente incorpora a los partidos de izquierda locales, sobre todo porque en sus bases sociales predominan los extranjeros. Sin embargo, este antifascismo no alcanza a convertirse en un tema de política nacional. Si bien el PCA -en el marco de la estrategia de "clase contra clase" que igualaba democracia burguesa con fascismo- había caracterizado al gobierno de Yrigoyen como "fascistizante", sólo a partir del golpe de Uriburu se instalará desde diferentes partidos y organizaciones políticas de izquierda una interrogación sobre los nuevos tiempos que recurre a la imagen de un "fascismo criollo", es decir, a una variante local de corporativismo que no alcanza a ser fascismo y que se percibe como una dictadura reaccionaria, tal el caso de la evaluación que del gobierno de Uriburu hizo Nicolás Repetto desde el Partido Socialista y el movimiento universitario a través de la figura de Ernesto Giudici. ${ }^{7}$

Pero hacia 1936, la lectura de la política argentina se hace en términos de una "fascistización" creciente en el seno de un sistema democrático que se ve jaqueado por enemigos externos -el imperialismo y el monopolio económicoe internos -los aliados de estos intereses que promueven las leyes represivas que anulan la libertad de expresión y asociación. Si en 1931 la dictadura de Uriburu representaba una forma de reacción de las elites ante los efectos de la democratización que supuso el gobierno de Yrigoyen, ahora la "fascistización" del gobierno de Justo era considerada como una característica constitutiva del "fenómeno universal fascista, que resulta de una gestación paulatina en el seno de la reacción imperialista" (Giudici 1936: 26-27).

6 Archivo General de La Nación (AGN). Fondo Documental Partido Comunista Argentino: Legajo 5, 3.364, "Impresos, periódicos, folletines, 1927-1935".

7 Repetto (1957: 12-15) y Giudici (1932: 107, 139-140 y 325). 
En resumen, el antifascismo de los intelectuales argentinos se constituye como tal a mediados de la década de 1930, incitado fundamentalmente por las experiencias de las asociaciones culturales del antifascismo francés -como el Comité de Vigilance des Intellectuels Antifascistes-; las organizaciones de solidaridad internacional en defensa de los perseguidos por el fascismo; el cambio en la estrategia de la Internacional Comunista en favor de los frentes populares; y por las políticas cada vez más restrictivas del gobierno de Justo respecto a los opositores políticos. En rigor, lo que caracteriza este momento de la historia política y cultural argentina es la extensión de los tópicos del antifascismo, los cuales se expresan en innumerables experiencias políticas y culturales, a veces como estrategias políticas que esconden en el marco de la constitución de frentes populares, un clasismo residual pero aún activo. Otras veces, como sensibilidad política que recorre una amplia gama de significaciones en un contexto en el que la política argentina se "internacionaliza", en la medida en que las referencias a modelos de organización social y política externos se vuelven moneda corriente en las ficciones orientadoras del destino de la nación, de allí el interés suscitado tanto por el fascismo como por el comunismo, de allí también la percepción a partir de 1935 de que el conflicto fascismo-antifascismo se dirime tanto en cada una de las naciones europeas como en la Argentina.

Por eso no sólo la Guerra de España impactará en amplios sectores de la opinión pública argentina constituyendo nuevas formas de solidaridad internacional contra el fascismo que en un extremo alcanza a manifestarse en el número de quinientos voluntarios locales en las Brigadas Internacionales en España. ${ }^{8}$ Sino también, una serie de "acontecimientos claves" que movilizan -desde la lucha en contra del antisemitismo y de la política inmigratoria restrictiva del gobierno de Justo hasta las respuestas locales frente a la muerte de Henri Barbusse y el asesinato de los hermanos Rosselli, líderes en el exilio del movimiento antifascista italiano GL-, un amplio abanico de experiencias asociativas culturales u obreras, la creación de publicaciones periódicas en la clave del compromiso político y la actividad de ciertos partidos políticos y grupos culturales, que comienzan ahora a articular desde sus dinámicas y tensiones internas el problema del antifascismo.

\section{El exilio de los universitarios judío-italianos}

La hipótesis del antifascismo como un conjunto de afectividades ideológicas convergentes se afirma aún más cuando se observa la amplitud de las manifes-

8 AA.VV. (1976: 38-41) y Trifone y Svarzman (1993: 84 y ss.). 
taciones asociativas y culturales que involucraron la acción de muchos intelectuales argentinos bajo el tópico del antifascismo. Un interesante campo de observación de este fenómeno lo representa el conjunto de respuestas que desde Argentina se dieron ante el exilio de los intelectuales judío-italianos que debieron emigrar debido a la aplicación de las "leyes raciales" de 1938, por parte del régimen fascista de Mussolini. ${ }^{9}$ El ejemplo es interesante en términos metodológicos porque permite mantener una comparación transversal entre grupos intelectuales de diversas latitudes y tradiciones, al tiempo de poder observar dos tipos de relaciones locales particulares: por un lado, entre antifascismo comunista y no comunista y, por el otro, entre antifascismo italiano en Argentina y antifascismo argentino. Es decir las relaciones entre la dimensión étnica y la dimensión política a propósito del tema del antifascismo. ${ }^{10}$

En un artículo publicado en 1989, Lore Terracini planteó que el tema de la mini-diáspora de intelectuales italianos hacia Argentina durante los años del nazi-fascismo no había generado todavía un estudio sistemático (1989: 335369). Sólo se contaba con un conjunto de testimonios variados que incluían desde las memorias de los protagonistas hasta una serie de artículos en periódicos que rememoraban la actuación particular de los más notables. La excepción era el estudio de Ada Korn sobre los aportes de italianos a la cultura argentina, pues presentaba una mirada de conjunto proponiendo una periodización en tres etapas que diferenciaba entre Quelli di prima, es decir, los que habían llegado a la Argentina desde el periodo de la gran inmigración hasta los años treinta, Gli indesiderabili, aquéllos perseguidos por el fascismo tanto por su carácter antifascista como por la condición de judíos, y Quelli successivi, aquéllos que llegaron después de la Segunda Guerra Mundial (Korn 1983: 172-196).

El artículo de Terracini vino a llenar en forma preliminar ese vacío historiográfico pues abordó en forma sistemática este problema a partir del estudio de un corpus de 11 emigrados, que compartían la condición de ser universitarios judíos. Entre ellos, los médicos Amedeo Herlitzka, Renato Segre, Eugenia Sacerdote de Lustig y Leone Lattes; el matemático Beppo Levi; el físico Andrea Levialdi; el filósofo Rodolfo Mondolfo; el geómetra Alessandro Terracini y su hermano Benvenutto Terracini (lingüista); el sociólogo Renato Treves y el profesor Giovanni Turin.

A partir de memorias, fuentes oficiales italianas y recuerdos directos, pues Lore Terracini era hija de uno de los exiliados -Alessandro Terracini- y en su

9 Sobre las leyes raciales, Collotti (1998).

10 Para el caso del exilio de los republicanos españoles, ver el exhaustivo trabajo de Schwartzstein (2001). 
infancia había experimentado el proceso de la emigración y el exilio, la autora pasa revista a los itinerarios biográficos y se detiene básicamente en tres problemas: el porqué de la elección de la Argentina como país de destino; las modalidades de inserción laboral, y la relación con Italia luego de la caída del fascismo. ${ }^{11}$ Entre las razones de la elección de la Argentina, la autora encuentra que para los exiliados italianos, el idioma español representaba problemas menores respecto del inglés, de allí la no elección de otros destinos. Sin embargo, no descarta que las oportunidades de trabajo ofrecidas desde aquí también jugaron un rol importante. Así todo, las modalidades de inserción laboral asumieron algunas variantes significativas que muestran un escenario de recepción medianamente favorable. Por ejemplo, Levi, Segre, los dos Terracini y Treves, encontraron su estabilidad laboral en las universidades del interior del país, mientras que Mondolfo, Levialdi y Turin, tuvieron que peregrinar entre diversos espacios intelectuales. Otros exiliados, como los médicos Herlitzka y Lattes, pese a su gran fama internacional, no actuaron en universidades y se dedicaron a actividades privadas ligadas con sus profesiones (Terracini 1989: 356 y ss.).

La relación con Italia sin duda fue contradictoria. Atípicos entre los emigrantes italianos debido a su carácter profesional y al carácter forzado de su decisión, también lo fueron respecto de la emigración de judíos: los exiliados italianos no hablaban yidish, no eran particularmente ortodoxos y estaban fuertemente vinculados a la cultura laica y humanista italiana. En algún sentido, una consecuencia de la leyes raciales fascistas fue la recomposición de una identidad en clave judía, hasta el momento adormecida y en proceso de integración a la sociedad italiana. ${ }^{12}$ En efecto, hacia 1933 un intelectual judío como Arnaldo Momigliano -más tarde exiliado en Gran Bretaña-, había sostenido que "la storia delle comunità ebraiche in Italia s'identifica con quella della formazione della loro cosciencia nazionale italiana e che tale formazione è paralella a quella della cosciencia nazionale nei piemontesi o nei napoletani o nei siciliani" (Dionisotti 1987: 558 y ss.).

A diferencia de los intelectuales judío-alemanes exiliados en Europa o Estados Unidos, quienes no podían dejar de identificar Alemania con el nazismo, cortando todo vínculo incluso lingüístico y cultural, los italianos judíos en la Argentina fueron menos drásticos con la interrogación acerca de la "italianidad" y en disolver sus lazos con Italia. Más allá de coyunturas desfavorables, entre Italia y el fascismo era posible establecer una distinción animada por las

11 Lore Terracini murió en Turín el 11 de diciembre de 1995.

12 "On sait que les lois raciales furent l'occasion pour beaucoup des juifs italiens d'un brusque réveil. Il leur fit prendre brutalement conscience d'une identité juive que beaucoup d'entre eux avaient mis en veilleuse". Cahiers du CEDEI (1999: 79). 
diferentes formas de resistencia que se desarrollaban tanto en las comunidades del exilio, como la que se estaba dando en el interior mismo de Italia. ${ }^{13}$ En efecto, la estrategia de resistencia del comunismo italiano de los años treinta, no pocas veces evaluó que se podían admitir las manifestaciones de desacuerdo que podían nacer del seno del propio régimen fascista como un componente importante de la confrontación antifascista. ${ }^{14}$

Después de la liberación, se abrió la posibilidad de que los emigrados retornaran a sus cátedras italianas. Amedeo Herlitzka, Leone Lattes, los hermanos Terracini y Renato Treves, regresaron entre 1946 y 1951. Andrea Levialdi lo hizo en 1962. Pero Rodolfo Mondolfo, Renato Segre y Beppo Levi prefirieron quedarse en la Argentina. ${ }^{15}$ El perfil de esta emigración se entiende mejor desde una perspectiva global como la que han expuesto recientemente Eleonora Smolensky y Vera Vigevani Jarach (1998). Para las autoras, quienes han estudiado desde la historia oral el fenómeno de la emigración judía de origen italiano entre 1938 y 1942, una de las particularidades de esta colectividad reside en la fugacidad de su existencia: "surgida ante la necesidad de sustituir los vínculos sociales perdidos se fue disolviendo a medida que desaparecían los factores de coerción". Si bien algunos de los casos estudiados coinciden con los presentados por Terracini, Smolensky y Jarach infieren de un total de alrededor de 60 entrevistas, la experiencia colectiva de cerca de un millar de judíos italianos arribados a la Argentina durante el periodo mencionado. El resultado del proceso ha sido la integración plena en la sociedad receptora, de tal suerte que en la actualidad los hijos y nietos de los exiliados se inscriben en categorías culturales y religiosas alejadas de las originales.

No discutiré aquí la utilización metodológica del concepto de "identidad", aunque es posible pensar que esta emigración haya sido en términos de identidad menos judía de lo que se supone por las razones ya mencionadas. Tal vez, la mayor predisposición a la integración se explique más en la debilidad original de esta identidad que en la pérdida abrupta de la misma. Esa predisposición a la integración parecía convivir bien con la conservación de la "italianidad" y podía estar ligada a las oportunidades laborales. Así todo, la argumentación de las autoras es lo suficientemente documentada como para sostener sus hipótesis con solidez.

Volviendo al núcleo original de exiliados universitarios italianos me propongo presentar aquí algunas ideas respecto de la relación entre los exiliados y ciertas experiencias antifascistas argentinas durante la década de 1930. Mi hipótesis

\footnotetext{
13 Sobre los intelectuales judío-alemanes exiliados, Palmier (1988: 376).

14 Rapone (1999: 7-34) y Agosti (1998: 101-112).

15 Terracini (1989: 358) y Treves (1990: 123).
} 
inicial plantea que los intelectuales italianos que llegaron a la Argentina entre 1938 y 1941, como consecuencia de la aplicación de las "leyes raciales" del fascismo, intentaron sus estrategias de inserción fundamentalmente a partir de las posibilidades que les abría su status socio profesional, en general de formación universitaria. ${ }^{16}$ La ligazón con las asociaciones antifascistas italianas en Argentina jugaron algún rol aunque secundario, más visible hacia el final del periodo que en el principio del proceso de residencia argentina de algunos de los exiliados. Por ejemplo, Renato Treves recuerda que conoció a Gino Germani en junio de 1941, en la ocasión de una conferencia que dictara en el Instituto de Sociología de la Facultad de Filosofía y Letras. Su vinculación fue primero intelectual en el marco de las actividades del Instituto, y más tarde política. El exilio de Germani puede ser pensado como un contraejemplo del devenir de los exiliados judío italianos, en la medida en que aquí jugaron más fuertemente los lazos y las afinidades políticas. En efecto, Germani había llegado a la Argentina en 1934 luego de haber sufrido un arresto y algunos meses de confinamiento político en Italia. Se vinculó al grupo antifascista que integraba Torcuato Di Tella, y se inscribió en la Facultad de Filosofía y Letras donde más tarde fue investigador, colaborando con Ricardo Levene, el director del Instituto. ${ }^{17}$ Ya hacia finales de 1934 y principios de 1935, Germani había colaborado en L'Italia del Popolo, un periódico fundado en Buenos Aires en 1917, y que para mediados de los años treinta había adoptado una línea de izquierda independiente pro republicana. Otros artículos aparecieron por esos años en el periódico antifascista La Nuova Patria, donde Germani abogó por la unidad de las fuerzas del antifascismo italiano en Argentina, desde la perspectiva de un joven emigrante que intentaba mostrar que el propósito de disciplinar a la juventud dispuesto por el régimen fascista no había alcanzado los objetivos esperados, y era posible advertir un antifascismo afectivo en la juventud italiana. Lo interesante de la etapa antifascista de Germani es que allí se asentarán gran parte de las preocupaciones sobre el funcionamiento de la sociedad, las formas de opresión estatal y el rol de la juventud en los regímenes autoritarios, que desarrollará más tarde desde una perspectiva teórica más sólida (Germani 2004: 45 y ss.).

Así todo, para los exiliados que habían formado parte del régimen o para quienes el régimen reconocía como aliados -como por ejemplo, el importante empresario Gino Olivetti había sido presidente de la Confederazione Fascista della Industria, y Margherita Sarfatti, antigua amante de Mussolini, ocupaba

16 Los exiliados son inmigrantes no ordinarios que deben al igual que los inmigrantes "económicos" procurarse su sustento en el país de recepción. Pero se diferencian de estos últimos por el hecho de que no pueden ingresar libremente en sus países de origen. (Dreyfus-Armand et Groppo: 1996: 7).

17 Treves (1990: 96 y ss.). 
un lugar importante en la cultura fascista- otros espacios como el Círcolo Italiano o la Banca Commerciale Italiana actuaron como ámbitos de socialización de estas elites, donde la categorización entre fascistas o antifascistas dejaba de tener el contenido que se evidenciaba en las organizaciones políticas mismas (Cannistrato y Sullivan 1992: 355, 383 y ss).

Para el caso de los intelectuales, es factible pensar que las redes de solidaridad de los antifascistas argentinos -de tradición democrática y liberal-tuvieron una importancia mayor que aquéllas de origen étnico sin duda porque el status profesional de este sector sumaba un elemento novedoso en la composición del flujo migratorio italiano tradicional (trabajadores manuales más o menos cualificados), y porque su condición de judíos introducía un elemento más de disrupción en el ya conflictivo mundo asociativo del antifascismo italiano en Argentina, pues intervenía agudizando las tensiones entre los fuoriusciti de prima data y unos exiliados que hasta el momento de las "leyes raciales" se encontraban más a menos acomodados en el marco de las posibilidades institucionales que brindaba el régimen en Italia. ${ }^{18}$

Por otra parte, es necesario recordar que aquellos que provenían de ámbitos universitarios en Italia, tenían en los hechos, al menos, un ámbito de convivencia con el fascismo ya que, por ejemplo, habían pasado -aunque fuese por simulación- por el juramento de fidelidad al régimen de todos los profesores impuesto en agosto de 1931. ${ }^{19}$ En este sentido, Renato Treves ha indicado que si en la emigración política el componente judío no fue relevante, tampoco en la emigración judía el componente político tuvo una importancia particular. ${ }^{20}$ Así todo, Aldo Garosci ha sido claro al señalar que si bien no es posible hablar de un antifascismo judío - tesis que más tarde retomará De Felice en su Storia degli ebrei italiani sotto il fascismo-, "la presenza all'estero, e sia pure in lontani paesi, come il Brasile e l'Argentina, di uomini come Rodolfo Mondolfo, Renato Treves, Tullio Ascarelli era indubbiamente un apporto al prestigio intellettuale dell'antifascismo emigrato". 21

\section{Un nuevo internacionalismo}

¿Cómo actuaron los intelectuales argentinos ante la experiencia de la diáspora intelectual italiana? Aquí cabe señalar algunos elementos que están presentes

\footnotetext{
18 L'Italia del Popolo, 30 de enero de 1939.

19 Boatti (2000), D'Orsi (2000) y Goetz (2000).

20 Treves (1990: 55).

21 Garosci (1953: 192-193).
} 
desde mediados de la década de 1930, como lo es el sentimiento más o menos difundido de una nueva solidaridad internacional no fundada ya sobre el tópico marxista del obrerismo, sino en la defensa de los derechos espirituales de la clase intelectual universal, ante el ataque sufrido por las políticas restrictivas de los estados fascistas. La idea de una "república general de la inteligencia" es visible hacia 1925 cuando se constituye en París, en el seno de la Sociedad de las Naciones el Institut International de Coopération Intellectuelle (IICI). Preocupado por legislar de forma corporativa sobre temas tales como los derechos de autor, los derechos de traducción, el intercambio cultural entre los intelectuales, científicos y escritores de todos los países, y los problemas de la organización intelectual, el $I I C I$ se inspira en una perspectiva pacifista que pretende construir en esta comunidad internacional los acuerdos que los gobiernos no lograron cuando se desatara la Primera Guerra Mundial.

Sin embargo, en el clima del antifascismo cultural de los años treinta y rehuyendo de las definiciones que tuvieran el marco político nacional como referencia, el IICI apeló no sólo a la metáfora de la République des esprits sino a la idea de la extensión internacional de la noción del intellectuel républicain, como un modelo de acción cultural que aseguraba el ejercicio de un humanismo racionalista (Trebitsch 1998: 58).

Con más beligerancia, hacia 1938 tanto L'Association Internationale des écrivains pour la défense de la culture (AIEDC) - de inspiración "cominterniana"-, como los PEN Clubs (que se definían por su independencia ideológica), acordarán una serie de acciones comunes en favor de los escritores víctimas de las persecuciones en los regímenes fascistas, en las que se declararán abiertamente opositores a toda forma de persecución racial o cultural, y en particular a las más recientes persecuciones antisemitas (Racine 1998: 39). El dato revela hasta qué punto el clima político internacional obligaba a definiciones más contundentes respecto del fascismo en los núcleos intelectuales, pues en la oportunidad del Congreso del PEN Club celebrado en Buenos Aires en 1936, en virtud de un pacto de no agresión entre los escritores, se había mantenido una posición de neutralidad respecto de un tema tan candente como la Guerra Civil Española, obligando incluso a retirar la moción de homenaje a Federico García Lorca, presentada luego del asesinato del poeta por la delegación española y catalana. ${ }^{22}$

También resulta interesante cómo en el PEN Club de Buenos Aires, la metáfora de la "internacional del espíritu" se vuelve un indicador de los significados presentes en el debate cultural local donde el criterio de distinción social y de la cultura como privilegio de las elites se vuelve elemento principal

22 XIVe. Congrés International des PEN Clubs, 5-15 septembre 1936. Discours et débats (1937: 149-150). 
de legitimación de la práctica intelectual, mientras desde otros ámbitos culturales se apela no sólo a una mayor distribución cultural (como por ejemplo, El Teatro del Pueblo), sino a la idea de la existencia de un arte revolucionario (González Tuñón 1936: 12-13).

Otras manifestaciones de solidaridad con los perseguidos por el fascismo están presentes en Argentina desde abril de 1935, como el Comité de Ayuda a las víctimas del fascismo en España, filial local de su homónimo parisino, presidido internacionalmente por el profesor Henri Wallon, e integrado en Buenos Aires por Alfredo Palacios, Aldo Cantoni, Augusto Bunge, Benito Marianetti, Sebastián Marotta y Miguel Contreras, entre otros. En junio de 1935, este agrupamiento intentó realizar un Congreso de Solidaridad, con el propósito de federar a los organismos de ayuda a los perseguidos por el fascismo en Europa, del cual participaron las fuerzas políticas de izquierda, aunque se advirtió la ausencia de las organizaciones obreras. Allí se propuso una organización que actuara a favor de los patronatos como movimiento de solidaridad, que amparara a los perseguidos fuera de sus países de origen, y que se articularan en una federación con bases jurídicas claras. ${ }^{23}$ Para diciembre de ese año, se constituye la filial local del Comité Mundial de Ayuda a las Víctimas del Fascismo, presidido por Romain Rolland. Ésta estaba integrada básicamente por políticos e intelectuales radicales, socialistas, demócratas progresistas y comunistas como José Peco, Emilio Ravignani, Aníbal Ponce, Augusto Bunge y Julio A. Noble.

Hacia 1939, cuando se constituya en París el Comité de Ayuda a los intelectuales españoles refugiados en Francia, otros intelectuales argentinos como Alberto Gerchunoff, formarán parte de esta agrupación, en un momento en que el problema de los refugiados españoles parece absorber el conjunto de las preocupaciones del antifascismo. ${ }^{24}$

También la prensa periódica no partidaria -como Crítica y La Nación-se manifestó alarmada ante la persecución de los intelectuales y políticos antifascistas en Europa, como en el caso del asesinato en Francia de los hermanos Carlo y Nello Rosselli -líder el primero del grupo antifascista italiano GL- acaecido el 9

23 Crítica, 10 de junio de 1935.

24 En Gerchunoff el tema de la persecución antisemita está fuertemente presente al menos desde mediados de 1938, cuando publica un artículo sobre Sigmund Freud y Stefan Zweig exiliados en Londres, a quienes denomina "heimatlos", hombres sin patria: "Y la gente de la ciudad fenecida (se refiere a Viena) aprisionó al viejo sabio (Freud), confiscó su imprenta, su dinero, sus libros, por el delito de pensar y por el delito de no ser dolicocéfalo esencialmente rubio, con entronque en los compañeros de Atila [...] Esa emigración del arte y de la sabiduría significa en el fondo un traslado de las patrias inciviles a los refugios de la civilidad". Gerchunoff (1938). Archivo Alberto Gerchunoff, Carpeta XVI y XVIII. Instituto de Investigaciones Históricas Emilio Ravignani. 
de junio de 1937, en manos de lo que la prensa parisina llamó La Cagoule, una asociación de extrema derecha que se constituyó en París luego del triunfo del Frente Popular, y que tenía importantes contactos con la OVRA (la policía secreta de Mussolini). ${ }^{25}$ Claro que en uno y en otro caso, las respuestas periodísticas no tuvieron el mismo tratamiento. La Nación hizo una lectura equidistante, donde sin dejar de mencionar la trayectoria de los actores antifascistas, primó el carácter de hecho policial de este suceso político. El tema aquí es seguir el proceso de la investigación, el sumario, cotejar versiones que se suceden con los días, hasta ir perdiendo en el camino del proceso investigativo el interés por el asesinato y llegar hasta la actividad clandestina de la OSARN. (Organisation secrète $d$ 'action revolutionaire nationale), de la cual La Cagoule formaba parte. ${ }^{26}$

Por el contrario, Crítica no sólo toma como redactores a conocidos personajes del exilio antifascista italiano en Argentina - como Mario Mariani-, sino que desde un principio sale del hecho policial para ver el contexto político en el que se dio el asesinato. Sus fuentes son la propia $G L$ y sus corresponsales en París, y su adhesión es clara no sólo con el antifascismo global (Crítica siempre se manifestará a favor de los republicanos españoles y de las propuestas frentistas), sino con una exaltación de la dimensión heroica del militante de GL, como el modelo de la acción antifascista. ${ }^{27}$

Así todo, el rol de las organizaciones solidarias ayudó más al fortalecimiento en la opinión pública de una idea del fascismo como "incivilización”, y como peligro para el desarrollo de la cultura, que al sostén específico de los perseguidos políticos. En rigor, éste se hizo posible gracias al rol de las relaciones personales en la salvaguardia individual, acciones raramente públicas que se hicieron en el nombre de un indiscutible y compartido ideal democrático universal. ${ }^{28}$

\section{La AIAPE o las relaciones entre comunismo y nación}

Con la puesta en marcha de la estrategia de los frentes populares, el Partido Comunista local -que hasta el momento había apostado por la estrategia de

25 Bourdrel (1970) y Kergoat (1986: 222 y ss.).

26 "Fueron asesinados en Francia los dos hermanos Roselli. Sus cadáveres han sido hallados en las inmediaciones de Bagnoles de l'Orne. Crimen político", La Nación, 12 de junio de 1937, p. 3 y "El sumario por el asesinato de los hermanos Rosselli. Ayer fue interrogado en París el acusado Robert Puireux de Fienne. Su automóvil”, La Nación, 14 de enero de 1938, p. 5.

27 Mariani (1937).

28 Una idea similar sobre el exilio argentino de los artistas plásticos españoles de filiación republicana, en Weschler (2002). 
lucha de clases- intentó incorporarse de un modo efectivo en el sistema político argentino. La creación en 1935 de la Agrupación de Intelectuales, Artistas, Periodistas y Escritores (AIAPE, 1935-1943), animada por el intelectual marxista Aníbal Ponce y por otros intelectuales en su mayoría de origen comunista o ligados afectivamente a la política cultural del Partido, desarrollaron una serie de reflexiones que si bien expresaron fuertemente la tensión existente entre solidaridad internacional y política local, tuvo como resultado la incorporación de la tradición liberal en la matriz y en la genealogía del pensamiento comunista argentino. ${ }^{29}$

En algún sentido, entre los marxismos posibles de mediados de la década de 1930, el de Aníbal Ponce y su admiración por las figuras del pasado liberal argentino (Sarmiento, Wilde, Echeverría), aparece como el de mayor probabilidad de recepción en la medida en que tanto su relación con la tradición liberal, como la composición de los aliados que se articulan en la Agrupación de Intelectuales, Artistas, Periodistas y Escritores (entre ellos Lisandro de la Torre, senador por el Partido Demócrata Progresista) imponen sus límites a la posibilidad de un marxismo más beligerante en un contexto en que la estrategia frentista favorece el dialogo político con antiguos enemigos. ${ }^{30} \mathrm{Si}$ el abandono de la estrategia de la lucha de clases fue una plataforma de gran importancia para los partidos comunistas europeos que intentaban sumarse a la corriente principal de la cultura democrática (Collier 1988: 31), en el caso argentino, la nueva estrategia significó el descubrimiento de un nuevo aliado político: el radicalismo, pero un radicalismo que distaba de ser la fuerza popular en ascenso de los tiempos del gobierno de Hipólito Yrigoyen (Corbière 1984: 55). No es extraño que Aníbal Ponce se convierta en el personaje mítico de esta izquierda intelectual, y que en la década de 1950 sea el PC el mentor de una operación que se presenta bastante funcional a una política de diálogo fecundo entre familias ideológicas que reconocen un mismo pasado fundacional: la tradición liberal. La vida de Aníbal Ponce (1898-1938) se convierte en el mito intelectual de una izquierda sin proletariado: Ponce es el intelectual marxista perseguido desde el Estado, que en 1936 es obligado a optar por el camino del auto exilio mejicano, para concluir sus días dos años más tarde con una muerte trágica en el momento de su maduración intelectual.

De algún modo, la conversión de Ponce en la figura intelectual del PCA a través de un devenir personal que lo llevó desde la adhesión a un ideal "sarmientino" al descubrimiento del marxismo, ilustra el intento de la construcción de una genealogía de los comunistas locales, quienes encuentran en el

29 Para una versión más detallada, Pasolini (2004).

30 Ponce (1974). 
mandato inconcluso de la Revolución de Mayo, un momento en el que filiar en la tradición política e intelectual argentina, una línea de continuidad histórica en clave comunista. ${ }^{31}$

En esta operación de invención de un origen lejano para "intelectuales nuevos", la figura de José Ingenieros alcanza el lugar también mítico de "maestro de la juventud". Sobre este aspecto, lo interesante es que la cultura antifascista de la AIAPE construyó toda una historiografía marginal de los ámbitos profesionales pero de gran impacto en la esfera pública -las obras de Héctor P. Agosti, Gregorio Bermann, Emilio Troise, Sergio Bagú, José P. Barreiro, las del propio Ponce son una prueba de ello- en la que las nociones de Ingenieros acerca de que el mandato revolucionario de Mayo había abortado en el proceso histórico argentino, y de que era necesario constituir una nueva elite que lo llevara a destino, se volvía una potente ficción orientadora para quienes veían en el "fascismo criollo" al enemigo que nuevamente frustraba la concreción de ese ideal.

Esa tradición liberal en retirada se hallaba jaqueada desde varios flancos: el golpe de Estado de 1930 y el nacionalismo de derecha y por el PCA, que si bien apostaba a la estrategia de los Frentes Populares, es decir, de la alianza con los sectores medios y la burguesía democrática, imaginaba aún en un horizonte político cercano crearía un proceso de bolchevización encabezado por lo que denominaban el campesinado argentino. ${ }^{32}$

Es indudable que se encuentra golpeada, y tal vez un indicador de ello sea el hecho de que la tradición liberal se refugia -entre otros espacios de la sociabilidad cultural y política- en una agrupación como la AIAPE, muy pronto liderada por los intelectuales del PCA, ahora definitivamente convencidos de la estrategia frentista bajo una defensa de valores integradores como "Democracia", "Justicia" y "Libertad". De este modo, se entiende mejor el lugar de Ponce desde su figura de animador inicial de la entidad hasta la instancia de productor del discurso dominante.

El espejo en el que se miran los intelectuales de la AIAPE, era el Comité de vigilance des intellectuels antifascistes, presidido por Paul Rivet. Pero si éste pareciera expresar un ejemplo de antifascismo exitoso, en la medida en que se observa una participación más clara de los intelectuales en la constitución del Frente Popular francés, no sólo como catalizador de alianzas sindicales, sino

31 Sobre la operación de invención de Ponce en clave heroica, Ponce (1938) y (1958).

32 "Lutter activement pour renforcer l'influence du P.C. au sein de la petite bourgeoisie des villes que se ruine [...] et en particulier lancer des revendication pour l'amélioration de leur condition economique" (sic.) Lettre au C.C. du PC d'Argentine pour le Congres du Parti, 17-11-33. AGN, Fondo Documental Partido Comunista Argentino: Legajos 11 y $13,3.360$ y 3.364 . 
accediendo a lugares políticos importantes a partir de elecciones como las municipales de mayo de $1935 .{ }^{33}$ En la Argentina ello no sucede no sólo porque el Frente no logra constituirse, sino porque estos intelectuales tienen un peso menor en el espacio específico de la política, más allá de que dominen en la sociabilidad cultural.

En síntesis, desde la AIAPE los intelectuales comunistas no dejaron de expresar su solidaridad general en favor de los perseguidos por el nazi-fascismo europeo, y de hecho, participaron en asociaciones como el Comité de Lucha contra el Racismo y el Antisemitismo (1937) y en las instituciones que se creaban en apoyo a la República Española. Sin embargo, la política cambiante de un PCA, muy obediente de las directivas de la Internacional Comunista, condujo al alejamiento de los intelectuales no comunistas de la AIAPE. Entre 1939 y 1943 la hegemonía comunista era ya indiscutible. Estos intelectuales, que en su mayoría habían nacido a la vida cultural en la AIAPE, se debatían entre discutir la historia de la nación, proponer la defensa de la cultura ante el avance del "fascismo criollo" y seguir con admiración el itinerario de la URSS como modelo sustitutivo de progreso social, el llamado "humanismo proletario" del que hablaba Aníbal Ponce (1938).

¿Qué posibilidades había en este espacio para incorporar la problemática de unos inmigrantes judío-italianos cuyo elemento común lo constituía además, el origen profesional universitario? Las fuentes sólo muestran que en la esfera del PCA, la preocupación por la dimensión étnica del antifascismo estuvo presente en las secciones idiomáticas, en particular hacia finales de la década de 1920 cuando un dirigente como Vittorio Codovilla -italiano de nacimiento- participó en la fundación de la Alleanza Antifascista Italiana, una asociación pro comunista que disputaba un lugar hegemónico en la representación del antifascismo italiano con la organización local de la Concentrazione d'Azione Antifascista. Así todo, Codovilla era menos un dirigente étnico y más un intermediario político entre el antifascismo de origen étnico, el PCA y la Internacional Comunista de la cual era el delegado en la Argentina, en un contexto en que se está solidificando la disciplina del comunismo local respecto de la organización central. ${ }^{34}$

33 Sobre el peso de la sociabilidad intelectual en el origen del Frente Popular francés, Racine-Furlaud (1986: 298-322), Winock (1999: 298-367), Ory et Sirinelli (1986: 93 y ss.) y Ory (1994: 94-95).

34 Vittorio Codovilla, uno de los fundadores del PCA, fue delegado de la Internacional Comunista en España, donde tuvo activa participación tanto en la dirección política del Partido Comunista Español como en la organización de las brigadas internacionales. La literatura trostkista argentina le atribuye importante participación en el desplazamiento de Largo Caballero por Negrín, y en la represión del POUM de Barcelona en mayo de 
También, durante este periodo el PCA alentó la disolución de los grupos étnicos dentro del movimiento obrero nacional, en particular el referido a la comunidad judía, y cuando en penumbras participó hacia 1937 el Comité de Lucha contra el Racismo y el Antisemitismo no dejó de expresar la tensión entre el judaísmo como identidad "nacional" amenazada y la política de alianzas que debía promover en el nivel local el Comité, llevando a importantes enfrentamientos entre algunos miembros judíos de la institución. ${ }^{35}$

Por lo tanto, no habrá lugar en este espacio para pensar en la integración de nuevos intelectuales con perfiles profesionales como los exiliados judíos italianos, más aún si se tiene en cuenta que algunos de ellos se encontraban más cercanos al socialismo liberal de tradición "gobettiana" y "rosselliana", que a una forma de marxismo materialista que ya se había puesto en cuestión en Italia desde el final de la primera postguerra, con la obra del filósofo Rodolfo Mondolfo (Asor Rosa 1975: 1536 y ss.). De allí que quienes participaron en las organizaciones del antifascismo italiano en Argentina (en particular Treves y Germani) lo hicieran hacia 1943-44, como colaboradores de la publicación Italia libre, órgano de la asociación del mismo nombre que proponía formar un frente antifascista con un marcado carácter anticomunista y aliadófilo (Fanesi 1994: 93 y ss.).

Asimismo, el peso de un perfil de algún modo "nacional" en los proyectos, e internacionalista en sus ideales, imponía límites a la incorporación de intelectuales perseguidos por el fascismo, como los universitarios italianos llegados al Plata. Es muy interesante observar que tanto en la revista Unidad (19351941), como en Nueva Gaceta (1941-1943), las publicaciones de la AIAPE, sólo hubo alguna referencia a los exiliados cuando se trataba de españoles republicanos. ${ }^{36}$ Esta distancia se presentó también entre la dirigencia del PCA y los comunistas italianos, quienes en 1935 habían constituido el Fronte Unico dei Partiti Operai Italiani. Esta experiencia establecía un pacto entre el Partido Comunista Italiano y el Partido Socialista Italiano en el exilio, para recuperar la unidad de acción de todas las fuerzas antifascistas, luego de la desaparición de la Concentrazione en 1934. Pero las lecturas de la realidad política que hacía el PCA fundamentalmente subordinaba el tópico antifascista a la posición antiimperialista, mientras que para el Fronte... de lo que se trataba era de lograr -al menos en esta instancia inicial- la mayor incorporación de fuerzas posibles en la clave del antifascismo (Fanesi 1994: 78-79).

1937. Jorge A. Ramos (s.d.: 264 y ss.). Una imagen similar en Elorza (1998: 118 y ss.). También, Schenkolewski-Kroll (1991: 91-107).

35 Sobre la presencia judía en el movimiento obrero argentino, Bilsky (1989: 44). 


\section{La revista Hechos e Ideas o el antifascismo de los intelectuales de la Unión Cívica Radical}

El antifascismo de los políticos e intelectuales de la Unión Cívica Radical se expresó a través de la revista Hechos e Ideas (1935-1941). Esta publicación mensual apareció en junio de 1935 y coincidió con el levantamiento de la abstención electoral que había asumido el radicalismo desde 1931. El objetivo principal era convertirse en instrumento para la difusión y discusión del pensamiento partidario, en un momento en que la situación del país se había modificado de tal manera, que eran necesarias reflexiones más atentas a la actualidad del mundo.

En términos generales, la revista expresó la tensión entre un "radicalismo político tradicional" ligado a las nociones de libertad política y económica, y un "radicalismo social moderno", que proponía la adopción de una posición intervencionista por parte del Estado como gerente de una más equitativa distribución de la riqueza. Esta posición intervencionista que además reclamaba el desarrollo del mercado interno ante una situación económica argentina que basaba su patrón de acumulación casi exclusivamente en el mercado externo, y que había visto sus límites con la crisis económica de 1929, encontraba su fundamento ideológico, principalmente en la obra del economista alemán Adolph Wagner (1835-1917), creador de una doctrina social y económica a la que denominó "socialismo de Estado" y en la que intentó conciliar al liberalismo con el socialismo (Piñeiro 1994: 295-315).

Ahora bien, en la propuesta de Hechos e Ideas dicha intervención no tiene como objetivo principal modificar radicalmente las estructuras sociales, $-\mathrm{O}$ mejor, las relaciones sociales- sino atenuar las desigualdades consolidando un Estado que haga realidad las doctrinas del bienestar social y supere, a la vez, al Estado liberal y al socialista.

El núcleo ideológico con que estos intelectuales y políticos jóvenes intentan diferenciarse, se articula a partir del tópico de la armonía de clases. No parece extraño, entonces, que en su segunda época (a partir de 1947), la revista apoye decididamente al gobierno del general Juan Domingo Perón, pues en él veía concretadas las aspiraciones sociales vislumbradas desde mediados de la década de 1930: desarrollo del mercado interno, nacionalización de los servicios públicos y redistribución del ingreso. Aunque desde luego en esa segunda época participó sólo una parte de quienes lo habían hecho en la primera (Cataruzza 1993: 269-289).

Sobre esos temas se establecieron las diferentes actitudes que enfrentaron a los radicales de la revista Hechos e Ideas sobre posiciones intervencionistas hasta 1941. Así todo, la revista expresó un acuerdo global respecto de la necesidad de la moralización de la política y del horizonte futuro del Estado. Tam- 
bién, Hechos e Ideas concibió su acción antifascista apoyándose en la noción de "totalitarismo", a partir de la cual definió tanto al fascismo (las experiencias de Italia y Alemania), como al comunismo soviético. De allí que desde la revista se criticara fuertemente el proyecto de Represión del Comunismo llevado adelante por el senador Sánchez Sorondo, pues partía de la idea de que sólo el peligro totalitario se encontraba en una fuerza política, pero tampoco se favoreció la constitución de un frente popular que incluyera al comunismo local.

En este marco, su preocupación por entender el fascismo se expresó en la colaboración de algunos de los miembros de GL, como Gaetano Salvemini, Luigi Sturzo, Carlo Rosselli, Francesco Nitti y Guido de Ruggiero. Ya en el primer número de la revista, Gaetano Salvemini presentará un estudio sobre la relación entre capital y trabajo en la Italia fascista que concluirá recién con su colaboración publicada en el número 4 . El ensayo, inicialmente de carácter económico, intenta demostrar que el fascismo como modelo de satisfacción de las aspiraciones obreras era una falacia. Salvemini sostiene que la base de la dominación fascista se apoya en un Estado corporativo que cercena los salarios obreros, y un Estado policial que contiene la conflictividad social. En el horizonte de conflictos, el autor ve no sólo los que se producirán entre capital y trabajo, sino también entre la clase burguesa y el incremento del papel de un Estado de carácter burocrático. ${ }^{37}$ En un artículo de abril de 1936, Salvemini nuevamente aborda el problema del fascismo para favorecer ahora la idea del impulso de la emigración en Italia como salida a la pacificación. ${ }^{38}$

El aporte de Carlo Rosselli que selecciona Hechos e Ideas se articulará también sobre la discusión del Estado. En un artículo titulado "La muerte se llama fascismo", Rosselli -bajo el seudónimo de Sincero- presentó la noción de que el Estado moderno expresaba la tensión entre administración y legalidad. El fascismo sería un típico modelo de Estado fuera de la ley que representaba la situación de necrosis a la que había llegado el organismo social europeo. ${ }^{39}$

En marzo de 1937, Hechos e Ideas se encargó de la edición en español de Bajo el signo del fascismo, de Salvemini. Y en ese mismo mes, Luigi Sturzo y Francesco Nitti colaboraron con dos artículos. El primero trató de conciliar el socialismo con el cristianismo, en una crítica a las formas totalitarias de Estado, que él veía expresadas tanto en el fascismo como en el comunismo: "El Estado totalitario suprime la libertad e introduce la supremacía de lo temporal sobre los fines éticos". ${ }^{40}$ También Nitti consideraba igualmente peligrosos a

37 Salvemini (1935: 349-354).

38 Salvemini (1936: 105-118).

39 Sincero (1935: 37 y ss.).

40 Sturzo (1937: 364). 
ambos modelos políticos, pero sobre todo, como productores de la ideología nacionalista que terminaba por anular las libertades ${ }^{41}$.

Para la revista Hechos e Ideas el problema central era tratar de pensar la forma más correcta de integrar las reformas sociales que pretendían hacerse desde el Estado con la defensa de la libertad política. En un artículo de abril de 1937, Guido de Ruggiero sostuvo la tesis de que el modelo de Estado liberal era la expresión más clara de la política en la Edad Moderna, y que por lo tanto, debía volverse a él pues en su seno se acogían todas las tensiones de la sociedad de un modo dialéctico. Claro que este modelo no era el de la Italia prefascista. Debía construirse, entonces, un nuevo Estado Político que superara al "Estado técnico, administrativo, dictatorial". ${ }^{42}$

Las colaboraciones de los miembros de GL se interrumpen en junio de 1938, con una semblanza biográfica de Carlo y Nello Rosselli a cargo de Gaetano Salvemini, motivada por el asesinato del líder de GL y de su hermano Nello. La Dirección de la revista afirmó que publicaba esas páginas como "contribución a la lucha antifascista en defensa de la democracia y contra todos los totalitarismos". 43

Más allá de la evidente operación de los editores de presentar una cercanía relacional e ideológica con los autores, es probable que las colaboraciones expresen más los contactos con antifascistas locales cercanos a GL, que con los exiliados mismos. Aunque no he podido establecer con certeza esa conexión, es posible constatar algunas relaciones importantes que podrían haber jugado un papel en este proceso. El editor de algunas obras de Rosselli en Argentina fue Sigfrido Ciccotti, quien en 1944 publicó algunos de sus artículos, entre ellos "Oggi in Spagna. Domani in Italia", en una compilación que llevó el título de Acción y Carácter-Escritos políticos y autobiográficos, con prólogo de Gaetano Salvemini. Ciccotti había sido miembro de la Concentrazione d'Azione Antifascista local, y en 1941, formó parte del ya mencionado grupo Italia Libre.

Desde su posición de Secretario de Italia Libre, Ciccotti se convirtió en el vínculo más potente que tenía en la Argentina Randolfo Pacciardi, quien desde Estados Unidos pretendía organizar una Legión de combatientes italianos del continente americano que fuera a pelear contra el fascismo en la Segunda Guerra. Ciccotti formaba parte del entorno del industrial italiano Torcuato Di Tella, uno de los financistas más importantes de la Concentrazione parisina y de la Italia Libre local. ${ }^{44}$

\footnotetext{
$41 \quad$ Nitti (1937: 384).

42 De Ruggiero (1937: 285 y ss.).

43 Salvemini (1938: 219 y ss.).

44 Baldini e Palma (1990: 8-14), Di Tella (h) (1993: 53) y Tobia (1993: 57-119).
} 
Pero lo que pareciera ser más evidente son los vínculos con los sectores socialistas españoles y su prensa periódica, en particular Leviatán, una revista editada en Madrid por Luis Araquistain cuyo propósito principal fue promover la radicalización del PSOE. También GL se hacía presente en Leviatán a través de los artículos que publicaba Aurelio Natoli, uno de sus miembros (Cataruzza 1994: 41).

En síntesis, los intelectuales y políticos de la revista Hechos e Ideas expresaron una modalidad de antifascismo que buscó en los aportes teóricos de algunos de los miembros de GL una serie de criterios que le permitieran pensar la realidad política local, desde una perspectiva que integrara la acción intervencionista del Estado con la libertad civil. La cuestión del fascismo introducía precisamente el problema de un Estado que convertido en actor había socavado las libertades civiles, de allí que el historiador y diputado radical Emilio Ravignani, confeso antifascista y asiduo colaborador de la revista, encontrara en el fascismo una expresión de la "instintividad" política, la ausencia absoluta de civilización, entendida como cultura cívica y como legalidad institucional ${ }^{45}$.

Otros debates presentes en GL, que enfrentaron a Rosselli con Emilio Lussu -como los problemas referidos a la organización del mundo obrero en el proceso de cambio social-, no tuvieron cabida en las páginas de Hechos e Ideas seguramente porque la propuesta de la armonía de clases era el espejo donde estos intelectuales se miraban (Brigaglia 1979). O, tal vez, porque concernían a dimensiones internas que no era conveniente presentar en el exterior. Y no era extraño que así sucediera: en un partido por demás heterogéneo, con una base social apoyada básicamente en las clases medias, con posiciones políticas que iban desde el antifascismo y el anticomunismo en sus círculos intelectuales, al neutralismo de la mayoría de los órganos ejecutivos del partido ante la Guerra de España, la cuestión de la insurrección obrera no se presentaba como un problema fundamental, en un contexto en que la Unión Cívica Radical abandona la postura abstencionista asumida desde el golpe militar de 1930 en favor de una actitud conciliadora con el gobierno del general Justo (Ciria 1975: 265).

\section{El Colegio Libre de Estudios Superiores o la red antifascista de los intelectuales "no comunistas"}

Separados de sus cargos universitarios y expulsados de las instituciones científicas, el camino del exilio se presentaba como la única salida no sólo desde el

45 Ravignani (1935). 
punto de vista vital, sino también laboral. El Colegio Libre de Estudios Superiores (CLES) y la red de solidaridad antifascista que se constituyó a través de él, fue el espacio asociativo donde los intelectuales italianos encontraron la posibilidad inicial de seguir desarrollando sus actividades profesionales.

El CLES había sido creado en mayo de 1930 por obra de algunos intelectuales de renombre en la cultura argentina del momento (entre ellos Roberto Giusti, fundador en 1908 de la revista literaria Nosotros). Concebido como un centro paralelo a la oferta de la universidad estatal, el Colegio se proponía contribuir al desarrollo de los estudios superiores, a partir de la constitución de una serie de "cátedras libres, de materias incluidas o no en los planes de estudios universitarios, donde se desarrollarán puntos especiales que no son profundizados en los cursos generales o que escapan al dominio de la Facultades". ${ }^{46}$

Con el golpe de Estado de 1930 y su política de represión global y "antirreformista" respecto de la universidad, el CLES se transformó en el reducto de gran parte de la oposición intelectual liberal-democrática, y hacia mediados de la década, en uno de los centros antifascistas por excelencia.

"Ni universidad profesional, ni tribuna de vulgarización", la propuesta del Colegio se debatió entre el acercamiento a las manifestaciones de la alta cultura y el objetivo de acercarla a la mayor cantidad de capas sociales posibles. En este sentido, el proyecto "pedagógico" que animaba a sus miembros colocó a la institución en una tensión muy clara frente a la universidad estatal, donde se advertía una disputa tanto al nivel del público como en lo referido al personal intelectual. En este sentido, el CLES acogió a los profesores expulsados de la universidad y a quienes mantenían sus cátedras universitarias les ofreció un espacio complementario de trabajo, incluso durante los gobiernos peronistas entre 1946 y 1955, constituyéndose allí una subcultura de oposición muy potente (Sigal 1991: 63-75).

$\mathrm{Al}$ año de su creación, el CLES comenzó a publicar la revista de divulgación Cursos y Conferencias, a través de la cual se intensificó un ideal pedagógico muy afín a la propuesta reformista que había desarrollado el Partido Socialista local desde finales del siglo XIX.

Si bien no ofrecía títulos académicos, contó entre sus asistentes con una gran cantidad de estudiantes universitarios y de profesores, seducidos por el tratamiento de la actualidad y por el perfil menos profesional que adquiría su propuesta educativa. Mediante los cursos de "información cultural", el CLES intentó captar a los sectores sociales medios bajos y se preocupó, en particular, por captar a maestros y maestras de la escuela primaria y secundaria, que 
pudieran multiplicar hacia abajo la labor pedagógica de la institución (Neiburg 1998: 46-47).

En la mentalidad de los sectores medios de la Argentina de entreguerras, la posibilidad del ascenso social y el acceso a la cultura letrada como un medio para lograrlo fueron tópicos dominantes del periodo. El CLES, entonces, no sólo expresó las afectividades ideológicas que lo colocaron en la oposición antifascista, sino también las pretensiones de ascenso social de esos sectores sociales. Hacia 1952, luego de veinte años de acción educativa, 608 profesores e intelectuales habían dictado 1551 cursos (77,55 anuales), y se habían desarrollado 13 conciertos educativos y 34 sesiones cinematográficas.

En este contexto de extensión de la cultura y la pedagogía a la sociedad civil -tópico recurrente en la izquierda del periodo-, no parece extraño que el carácter enciclopedista de la propuesta facilitara la adopción de intelectuales ante todo reclamados por su saber específico a la vez que por sus posiciones antifascistas. Así, los universitarios judíos italianos encontraron un espacio de actuación profesional inicial junto a otros inmigrantes y exiliados no judíos de tradición socialista como Torcuato Di Tella, ${ }^{47}$ Gino Germani y Mario Mariani. ${ }^{48}$ La revista del Colegio también acogió las opiniones de exiliados políticos como Giuseppe Tuntar, un comunista del Friuli (Norte italiano) que había enfrentado en el seno de la Alleanza Antifascista a Vittorio Codovilla, y que proponía una línea de unión de las fuerzas del antifascismo en exilio -sobre todo con la Concentrazione local-, mientras que el Segundo Congreso de la Alleanza en Berlín (1929) había establecido una política decididamente contraria a unidad, lo que motivó el alejamiento de Tuntar de las filas comunistas (Fanesi 1994: 50).

En 1939, Cursos y Conferencias publicó "El antiguo imperialismo romano y el neo-imperialismo italiano: Cartago y Túnez", un artículo en el que Tuntar sostuvo la tesis de que la política expansionista del Duce se presentaba muy

47 Más allá de sus estudios universitarios, la participación de Di Tella en el CLES se entiende más por su carácter de importante empresario financista de la institución y reconocido antifascista.

48 Mario Mariani nació en Roma en 1894. Vivió en EEUU y en Berlín, donde fue corresponsal de Il Secolo de Milan y de Il Messagero de Roma. Durante la Gran Guerra se adhirió en forma independiente a las posiciones del socialismo italiano, y luego se dedicó a una activa producción literaria escribiendo varias obras de éxito, y fundando las revistas Novella y Comoedia. Obligado a exiliarse por su oposición al fascismo, Mariani recaló en Buenos Aires luego de otros destinos, y allí formó parte del plantel periodístico del diario Crítica, que apoyaba en modo beligerante las posiciones del antifascismo local. Murió en San Pablo en 1951. Cursos y Conferencias. Revista del CLES, XIV, VII, 10-11, enero-febrero 1939, p. 1.165; Petriella y Sosa Miatello (1976: 423) y Falco (1980). 
funcional al objetivo de división territorial europea, en el que aparecía una Europa central bajo el control del nazismo y un Mediterráneo dentro de la órbita del fascismo, un escenario en el que se veía fenecer "la antorcha de la libertad humana". 49

En esta clave del antifascismo afectivo, Cursos y Conferencias publicó también algunas colaboraciones de Ignazio Silone, entre ellas, un capítulo de su libro La escuela de dictadores. El capítulo fue promocionado como parte de un estudio que publicaría más tarde la Editorial Losada, y en él se alertaba sobre las condiciones particulares que habían hecho posibles el fascismo y el nacional-socialismo, y que aún persistían en su propagación.

El ejemplo es muy interesante pues da indicios de otra de las vertientes relacionales que se articulaban alrededor del CLES: la vinculación con los exiliados españoles republicanos y su participación en la industria editorial. En efecto, en agosto de 1938 Francisco Romero, Amado Alonso y Attilio Rossi participaron en la fundación de la Editorial Losada, un ámbito que reunió y editó muchas de las obras de los republicanos españoles en el exilio, entre ellos, Rafael Alberti, Lorenzo Luzuriaga, Guillermo de Torre y Manuel García Morente (Zulueta de 1999: 58).

La Editorial Losada publicó también escritos de Mondolfo, de Terracini y de otros italianos residentes en la Argentina, a partir de los contactos que se establecieron con Attilio Rossi, un exiliado antifascista que había dejado Italia en 1935, y que una vez en Buenos Aires, ideó una colección económica de grandes obras editada por la Editorial Espasa-Calpe (Treves 1990: 69).

La posibilidad del ingreso a la vida cultural local de los exiliados se articuló a partir de la red de intelectuales y políticos antifascistas que se expresaba fundamentalmente en el CLES, más allá de su vinculación con algunas universidades nacionales. Un indicador de estos mecanismos lo representa el itinerario de Rodolfo Mondolfo:

En 1938 perdí mis cátedras y, al año siguiente, abandoné Italia. No podía publicar nada, ni siquiera tenía acceso a las bibliotecas. Debía permanecer recluido en casa. Mis hijos ya se habían doctorado y tampoco podían ejercer. Emigrar se convirtió en una necesidad absoluta. Recordé entonces que en la Argentina vivía un señor que había traducido algunos trabajos míos. Era Marcelino Alberti. Le pregunté en una carta si podía conseguirme un permiso de desembarco, cosa que era muy difícil. Alberti interesó a Alfredo Palacios en mi problema. Al mismo tiempo, el filósofo italiano Giovanni Gentile, que había sido ministro de Mussolini, pero también amigo personal mío desde la época de estudiantes, espontáneamente le escribió a Alberini, que era decano universitario en Buenos Aires. Le pidió que me 
invitara para dictar un curso. Así sucedió. Con la invitación de Alberini y las gestiones de Palacios, pude conseguir el ingreso a la Argentina para mí y mi familia. ${ }^{50}$

En efecto, el senador socialista Alfredo Palacios consiguió la visa para Rodolfo Mondolfo y a su llegada éste comenzó a dictar cursos en el CLES. Mondolfo dictó 5 conferencias en 1939; 3 en 1940; 2 en 1942; 2 en 1943; y 1 en 1946. Allí pudo establecer excelentes relaciones personales con colegas de gran prestigio intelectual local y peso institucional como el filósofo Francisco Romero, importante animador del Colegio desde su creación, y de otros espacios de la cultura socialista. En 1940, se incorporó a la Universidad de Córdoba, y en 1947 comenzó a dictar cursos en la Universidad de Tucumán.

El matemático español residente en Buenos Aires, Julio Rey Pastor, contribuyó a la llamada de Beppo Levi y Alessandro Terracini. El primero fue contratado por la Universidad del Litoral para dirigir un Instituto de Matemáticas, y el segundo por la Facultad de Ingeniería de la Universidad de Tucumán. Más tarde llegará Benvenuto Terracini, quien gracias a las gestiones de su hermano y la ayuda de Amado Alonso, Director del Instituto de Lingüística de la Facultad de Filosofía y Letras (UBA), ocupará un importante lugar académico en Tucumán. También Treves recalará allí, esta vez con el apoyo de Carlos Cossio, profesor de Filosofía del Derecho en la Universidad de La Plata. Al menos Rey Pastor, Carlos Cossio y Carlos Alonso integraban el plantel del CLES desde 1931.

El itinerario de Renato Treves es muy ilustrativo también del funcionamiento de la red de solidaridad socio profesional que se articula a partir de los contactos entre el mundo universitario italiano e intelectuales uruguayos y argentinos. Luego de que las "leyes raciales" lo excluyeran de participar en un concurso en la Universidad de Urbino, en octubre de 1938 Treves se embarcó en Nápoles con destino a Montevideo. Llevaba con él una carta de presentación del penalista turinés Eugenio Florian, quien solicitaba al colega uruguayo Carlos Salvagno Campos lo presentara a Eduardo J. Couture, abogado e importante profesor en la Facultad de Derecho en Montevideo. Couture además tenía contactos intelectuales muy sólidos con Piero Calamandrei (Losano 1998: 43).

Hasta febrero de 1939, Treves residió en Montevideo, dictó algunas conferencias y publicó en la Revista de derecho, jurisprudencia y administración, dirigida por Couture, el artículo "Neo-hegelismo italiano y neo-kantismo alemán en el pensamiento jurídico contemporáneo". Pero la realización de un

50 Rodolfo Mondolfo a Alberto Szpunberg, "El último reportaje a Rodolfo Mondolfo: un testigo del siglo", Clarín, 9 de diciembre de 1976. 
congreso de sociología en Buenos Aires lo contactó con Carlos Cossio, y éste gestionó su ingreso en la Universidad de Tucumán para dictar "Introducción al Derecho" (Treves 1990: 65).

Es interesante destacar el papel de mediador cultural de Eduardo Couture en el contexto de la red de solidaridad antifascista: "Senza posa Couture si prodigó per acogliere, consigliare e sistemare al di là dell'Atlantico gli intellettuali europei dei più diversi paesi d'origine, spagnoli, italiani, tedeschi, francesi" (Treves 1957: 468-473). También cuando el peronismo expulsó a muchos profesores de sus cargos universitarios, Couture tuvo un rol muy importante en la instalación de estos profesores en la Universidad de la República y aunque la posibilidad de crear una filial del CLES en Montevideo se vio frustrada hasta 1955, el Colegio no dejó de recordar que los vínculos de amistad con Couture eran tan antiguos como la creación misma de la institución. ${ }^{51}$

Una mención especial merece la relación de esta emigración con el antifascismo judío en la Argentina. En efecto, el antifascismo judío se expresó en varias instituciones -una de ellas la Delegación de Asociaciones Israelitas Argentinas (DAIA), creada en 1935-, pero alcanzó un importante desarrollo a través del grupo de la revista Judaica, nacida en 1933. Judaica planteó un diálogo muy potente entre marxismo y judaísmo, proponiendo a la Unión Soviética como el modelo ideal de organización política y social, pues ésta era visualizada como "el único estado en el cual los judíos pueden hacer su propia vida, no sólo como individuos sino también como nación". ${ }^{2}$ La idea de la URSS como destino de la nación judía está presente al menos desde noviembre de 1935, cuando el Comité Pro Colonización Israelita en Birobidyan organizó la visita de la delegada soviética Gina Meden, quien promovió este proyecto en las colonias judías instaladas en las provincias de Santa Fe y Chaco. ${ }^{53}$

En el plano interno, Judaica se propuso revalorizar la identidad judía disputando una lucha que se dio en dos planos. Por un lado, atacó a las expresiones de la derecha nacionalista argentina que estigmatizaban al judío como portador de calamidades sociales. ${ }^{54}$ Por otra parte, disputó en el seno mismo de la comunidad una batalla ideológica que, en un nivel, intentó rescatar el aporte judío a

51 Cursos y Conferencias, XLVII, 271, diciembre de 1955, p. 470.

52 Weinstein (1937).

53 AGN, Fondo Documental Agustín P. Justo. Ministerio del Interior, Caja 47, Legajo 3.229, documento n ${ }^{\circ}$ 18, "Sección Especial, Buenos Aires, 4 de junio de 1936".

54 Es muy interesante observar la disputa que se da alrededor de la figura de Richard Wagner, pues Judaica intenta demostrar que el antisemitismo de Wagner se debe a una actitud de resentimiento respecto de su "verdadero" padre, un actor de origen judío. La referencia a la estética de Wagner como elemento de distinción social está presente en gran parte de la elite intelectual argentina desde fines del siglo XIX, pero en los años treinta 
la cultura argentina desde los tiempos de la colonia española, mientras que en otro, pugnó por disciplinar a los miembros de la propia comunidad cuando sus propuestas culturales parecían reproducir los estereotipos antijudíos. ${ }^{55}$

¿Qué relación establecieron los exiliados con las expresiones instituciones de la comunidad judía local? Si ella existió, seguramente fue más el resultado de solidaridades individuales que de vinculaciones institucionales, pues, como lo recuerda Treves, los intereses de los exiliados italianos judíos corrían por carriles diferentes de los de la comunidad judía local: "[...] costituite da immigranti provenenti da paesi dell' Europa Orientale che, fuggiti dalle persecuzioni dell' inizio del secolo, avevano lingue, tradizioni, interessi diversi dai nostri" (Treves 1990: 105).

En resumen, el CLES expresó una de las alternativas que asumió una red de solidaridad antifascista movilizada por los intelectuales locales no comunistas. Articulada también con otros espacios de la vida cultural, esta red dio lugar a la participación de los exiliados italianos, quienes lo hicieron a veces como conferencistas y otras como docentes a cargo de cursos específicos. Más allá de los perfiles profesionales diferenciales y de su calidad intelectual, el exilio en Argentina de los italianos universitarios judíos no fue un salto al vacío. Esta experiencia se expresó desde el inicio a partir de un tejido relacional que articuló dos tópicos fundamentales: el carácter de perseguidos políticos movilizó unas afectividades que los colocaron en el amplio campo ideológico del antifascismo local, mientras que sus perfiles profesionales los acercaron a las necesidades de una vida intelectual que se movía entre los criterios de actualización del pensamiento y el de la pedagogía para la sociedad civil. En este sentido, el exilio intelectual italiano significó un aporte importante para la cultura argentina.

A lo largo del periodo de exilio, algunos de ellos pudieron convertirse en figuras notables de la vida cultural argentina, pues ayudaron a desarrollar y consolidar centros de estudios y líneas nuevas de investigación de gran impacto en la vida universitaria local, como lo atestiguan los itinerarios de Rodolfo Mondolfo, quien no regresó a Italia una vez caído el fascismo, y Renato Treves, quien más allá de su retorno, no dejó de mantener fluidos contactos intelectuales y afectivos con el mundo intelectual argentino.

Así todo, en el total de la actividad cultural del CLES durante el periodo 1930-1951, la actividad de los exiliados representó apenas el 5 por ciento. Pero esa participación posibilitó la extensión y la permanencia de unos lazos

alcanza otra significación pues se vuelve un tópico de identidad de la derecha nacionalista a partir de una matriz global de admiración de la cultura alemana. 
que no dejaron de activarse cuando las situaciones políticas de Italia y Argentina, en la evaluación de los actores, invertían sus escenarios. No es extraño, entonces, que el CLES recibiera con alegría la visita de Guido de Ruggiero en 1946, y que a través de sus conferencias se ilustrara sobre las bondades de las libertades democráticas recuperadas en Europa en el contexto del peronismo triunfante en las elecciones de febrero de ese año. Es sintomático de la percepción de una derrota, el conciliatorio artículo de Treves publicado en la revista del CLES en el que -ya desde su país natal- elogiando las cualidades intelectuales de Mondolfo invitaba a las autoridades peronistas a estrechar las relaciones institucionales y académicas con Italia, pues hasta el momento ellas habían sido el producto de unas voluntades individuales a contramano de los intereses del Estado argentino. ${ }^{56}$ Pero si bien con ello se trataba de limitar los efectos que la política del nuevo gobierno pudiera destinar para con los exiliados italianos que todavía permanecían en el país, estaba claro que la percepción general era la de una reedición en la periferia atlántica de las condiciones del fascismo europeo.

\section{Consideraciones finales}

En 1952, el intelectual socialista Dardo Cúneo, ex integrante de la AIAPE durante los años treinta, se preguntaba si en verdad -luego de la resistencia antifascista y de la guerra mundial- el "acto fascista" había terminado. Para él no sólo la respuesta era negativa, sino que lo veía prosperar en las zonas de economía demorada, de capitalismo incompleto, de expansión contenida, "de resentimiento de masa barbarizado y de resentimiento nacionalista". Desde la matriz socialista de Cúneo, la alusión a la Argentina del momento resulta inevitable. Se preguntaba si la nueva lucha antifascista consumiría también - como en Europa - a toda una joven generación. Pero no podía evitar sostener que la acción antifascista significaba antes y entonces, la faz inmediata de una profunda revolución en nombre de la libertad (1932: 33 y 64) ¿Persistencia en los años cincuenta de las situaciones políticas que dominaban en los años treinta o mantenimiento de una retórica que evidencia todavía el peso de una sensibilidad política en los esquemas interpretativos de la realidad nacional? Tanto desde la AIAPE, como desde la revista Hechos e Ideas y en el Colegio Libre de Estudios Superiores, el tópico de la defensa de las libertades humanas está fuertemente presente, pero cada grupo construyó un antifascismo a su medida, en función de los marcos de referencia internacionales, las necesidades en las 
alianzas políticas locales, y unas redes de solidaridad intelectual más o menos permeables al sostenimiento de unos exiliados ligados más al campo profesional que a los lazos políticos o ideológicos.

Así todo, esa acción del antifascismo global ayudó a crear la conciencia acerca de un enemigo común (el fascismo en la versión comunista, el totalitarismo según radicales y socialistas), un clima de época en el que la tradición liberal democrática se refugió en los avatares políticos del mundo de entreguerras. En este sentido, la propuesta de Renato Treves no hace más que ilustrar la presencia y no el residuo de una sensibilidad ideológica que se había constituido como tema de política nacional a mediados de los años treinta, pero que el advenimiento del peronismo al poder ayudó a prolongar en términos temporales al menos en las retóricas y las justificaciones de esas familias políticas argentinas para las que el peronismo significaba la versión vernácula del nazi-fascismo.

\section{Bibliografía y fuentes citadas}

“Acta de Fundación” (1953). En: Veintidós años de labor: 20 de mayo 1930-16 de julio 1952. Buenos Aires: edición del CLES, pp. 3 y ss.

Archivo General de la Nación (AGN), Fondo Documental Partido Comunista Argentino: Legajos 11 y 13, 3.360 y 3.364 .

AGN, Fondo Documental Partido Comunista Argentino: Legajo 5, 3.364, "Impresos, periódicos, folletines, 1927-1935".

AGN, Fondo Documental Agustín P. Justo: Ministerio del Interior, Caja 47, Legajo 3.229, documento ${ }^{\circ}$ 18, "Sección Especial, Buenos Aires, 4 de junio de 1936".

AA.VV. (1976): Le Brigate Internazionali. La solidarietà dei popoli con la Repubblica Spagnola, 1936-1939. Milano: La Pietra.

AA.VV. (1963): Fascismo e antifascismo (1918-1936). Lezioni e testimonianze. Milano: Feltrinelli Editore.

Agosti, Aldo (1998), "Un front populaire avec les fascistes? Les communistes et l'anomalie italienne". En: Wolikow, Serge/Bleton-Ruget Annie (sous la direction de) (1998): Antifascisme et nation. Les gauches européenes au temps du Front populaire. Dijon: Université de Bourgogne, Editions Universitaires, pp. 101-112.

Asor Rosa, Alberto (1975): Storia d'Italia, V, IV, (Dall'Unità a oggi). Torino: Einaudi.

Baldini, Alexandra/Palma, Paolo (1990): Gli antifascisti italiani in America, 1942 1944. Firenze: Le Monnier.

Bilsky, Edgardo (1989): "Etnicidad y clase obrera: la presencia judía en el movimiento obrero argentino". En: Estudios Migratorios Latinoamericanos, 11, pp. 27-47.

Bisso, Andrés (2001): "La recepción de la tradición liberal por parte del antifascismo argentino". En: Estudios Interdisciplinarios de América Latina y el Caribe, 12, 2, pp. 85-113.

Boatti, Giorgio (2000): Preferirei di no. Torino: Einaudi.

Bourdrel, Philippe (1970): La Cagoule. Paris: Albin Michel. 
Brigaglia, Manlio (1979): “Emilio Lussu e Carlo Rosselli: il socialismo 'diverso' di 'Giustizia e Libertà'”. En: Lussu Emilio: Lettere a Carlo Rosselli e altri scritti di "Giustizia e Libertà, (a cura di Manlio Brigaglia). Sassari: Editrice Librería Dessi, p. 19.

Camarero, Hernán (2003): A la conquista de proletariado. La experiencia comunista en el mundo de los trabajadores de Buenos Aires, 1925-1935. Tesis de doctorado. Universidad Torcuato Di Tella.

Cane, James (1997): “'Unity for the Defense of Culture': The A.I.A.P.E. and the Cultural Politics of Argentine Antifascism, 1935-1943 ”. En: Hispanic American Historical Review, 77, 3, pp. 443-469.

Cannistrato, Philip/Sullivan, Brian (1992): Il Duce's Other Woman. New York.

Cattaruzza, Alejandro (1993): "Una empresa cultural del primer peronismo: la Revista 'Hechos e Ideas' (1947-1955). En: Revista Complutense de Historia de América, 19, pp. 269-289.

- (1994): "Las huellas de un diálogo. Demócratas radicales y socialistas en España y Argentina durante el periodo de entreguerras". En: Estudios Sociales, IV, 7, pp. 29-48.

Ciria, Alberto (1975): Partidos y poder en la Argentina moderna (1930-1946). Buenos Aires: Ediciones de la Flor.

Clarin (Buenos Aires).

Collier, Peter (1988): "Sueños de una cultura revolucionaria: Gramsci, Trotski y Breton". En: Debats, 26, p. 31.

Collotti, Enzo (1998): "La politica razzista del governo fascista", ponencia presentada en el Convegno L'invenzione del nemico. Sessantesimo anniversario della promulgazione delle Leggi Razziali. Istituto Nazionale per la Storia del Movimento di Liberazione in Italia. Roma: Ministero della Pubblica Istruzione, pp. 1-7.

Corbiére, Emilio (1984): Orígenes del comunismo argentino (El Partido Socialista Internacional). Buenos Aires: CEAL.

Crítica (Buenos Aires).

Cúneo, Dardo (1952): Cuaderno de milicia. Buenos Aires: Logos Editores.

Cursos y Conferencias. Revista del CLES (Buenos Aires).

D’Orsi, Angelo (2000): La cultura a Torino tra le due guerre. Torino: Giulio Einaudi Editore.

De Ruggiero, Guido (1937): "La crisis del liberalismo". En: Hechos e Ideas. Revista Radical II, 20, pp. 285 y ss.

Di Tella, Torcuato (h) (1993): Torcuato Di Tella: Industria y política. Buenos Aires: Thesis.

Dionisotti, C. (1987): "Ricordo di Arnaldo Momigliano". En: Annali della Scuola Normale Superiore di Pisa, III, XVII, 3, pp. 58 y ss.

Dreyfus, Michel et al. (Sous la direction de) (2000): Le siècle des communismes. Paris : Les Éditions de l'Atelier/Éditions Ouvrières.

Dreyfus-Armand, Geneviève/Groppo, Bruno (1996): “Objetifs de la journée d'études 'Exilés et réfugiés politiques dans la France du Xxe. Siècle"'. En: Materiaux pour l' histoire de notre temps, 44. Nanterre: Association des Amis de la BDIC et du Musée, p. 7. 
Droz, Jacques (1985): Histoire de l'antifascisme en Europe, 1923-1939. Paris: Éditions La Découverte.

Elorza, Antonio (1998): “La 'nation éclatée' : Front populaire et question national en Espagne”. En: Wolikow, Serge/Bleton-Ruget, Annie (sous la direction de), Antifascisme et nation. Les gauches européenes au temps du Front populaire, Dijón: Université de Bourgogne, pp. 113-118.

Falco, Emilio (1980): Mario Mariani, tra letteratura e política. Roma: Bonacci Editore. Fanesi, Pietro Rinaldo (1994): El exilio antifascista en la Argentina, I. Buenos Aires: CEAL.

Furet, François (1995): Le passé d'une ilussion. Essai sur l'idée communiste au XXe. Siècle. París: Robert Laffont/Calmann-Lévy.

Garosci, Aldo (1953): Storia dei fuorusciti. Bari: Laterza.

Gerchunoff, Alberto (10 de junio de 1938) : "Genios en emigración”, La Semana de Buenos Aires. Archivo Alberto Gerchunoff, Carpeta XVI y XVIII. Instituto de Investigaciones Históricas Emilio Ravignani.

Germani, Ana Alejandra (2004): Gino Germani: del antifascismo a la sociología. Buenos Aires: Taurus.

Giudici, Ernesto (1932): Ha muerto el dictador pero no la dictadura. Buenos Aires: ExLibris.

- (1936): Represión obrera y democrática. Buenos Aires.

Goetz, Helmut (2000): Il giuramento rifiutato. I docenti universitari e il regime fascista. Firenze: La Nuova Italia.

González Tuñón, Raúl (1936): La rosa blindada. Buenos Aires: Federación Gráfica Bonaerense.

Grillo, María Victoria (2001): "L'antifascisme dans la presse italienne en Argentine: le cas du journal L'Italia del Popolo (1922-1925)”. En: Devoto Fernando/González Bernaldo, Pilar: Emigration politique. Une perspective comparative. Espagnols et italiens en France et en Argentine, XIXe-XXe siécles. Paris: 1'Université Paris 7 Denis Diderot-CEMLA-L' Harmattan, pp. 145-170.

Karduner, Luis (1937): “Carta abierta a César Tiempo (Con motivo del estreno de 'Pan Criollo')". En: Judaica, IV, 45, p. 43.

Kergoat, Jacques (1986): La France du Front populaire. Paris: Éditions la découvert.

Korn, Ada (1983): "Contributi scientifici degli italiani in Argentina nel ventesimo secolo". En: Korn Francis (a cura di): Euroamericani. La popolazione di origine italiana in Argentina, II, Torino: Fondazione Giovanni Agnelli, pp. 72-196.

La Nación (Buenos Aires).

Leiva, María del Luján (1983): "Il movimento antifascista italiano in Argentina, 19221945", en: Bezza Bruno (a cura di): Gli italiani fuori d'Italia. Milano: Fondazione Brodolini, Franco Angeli, pp. 549-582.

L'Italia del Popolo (Buenos Aires).

Losano, Mario (1998): Renato Treves, sociologo tra il vecchio e il nuovo mondo. Milano: Edizioni Unicopli.

Mariani, Mario (1937): "En el aniversario de la muerte de Matteotti, dos crímenes más”. En: Crítica, 12, 14, 15, 17, 18 de junio. 
Nascimbene, Mario (1990): "Fascismo y antifascismo en la Argentina, 1920-1945". En: AA.VV.: C'era una volta la Merica. Immigrati piemontesi in Argentina. Cuneo: L'Arciere, pp. 137-142.

Neiburg, Federico (1998): Los intelectuales y la invención del peronismo: Estudios de antropología social y cultural. Buenos Aires: Alianza Editorial.

Nitti, Francesco (1937): "El nacionalismo como negación de la libertad". En: Hechos e Ideas. Revista Radical, II, 19, p. 364.

Nueva Gaceta. Revista de la AIAPE. (Buenos Aires).

Ory, Pascal (1994): La belle illusion. Culture et politique sous le signe du Front populaire, 1935-1938. Paris: Plon.

Ory, Pascal Jean/Sirinelli, François (1986): Les intellectuels en France, de l'Affaire Dreyfus à nos jours. Paris: Armand Colin.

Palmier, Jean-Michel, (1988): Weimar en exil. Le destin de l'émigration intellectuelle allemande antinazie en Europe et aux Etats-Unis, 1. Paris: Payot.

Pasolini, Ricardo (2001): 'Exil italien et antifascismes dans l' Argentine pendant les années trente: la place des intellectuels". En: Devoto Fernando/González Bernaldo, Pilar: Emigration politique. Une perspective comparative. Espagnols et italiens en France et en Argentine, XIXe-XXe siécles. Paris: 1'Université Paris 7 Denis DiderotCEMLA-L' Harmattan, pp. 171-199.

- (2004): "Intelectuales antifascistas y comunismo durante la década de 1930. Un recorrido posible: entre Buenos Aires y Tandil". En: Estudios Sociales, 26, XIV, pp. 81-116.

- (2004): La utopía de Prometeo. Cultura antifascista e identidad comunista en la Argentina: entre París, Buenos Aires y Tandil, 1935-1976. Tesis de Doctorado. Interuniversitario en Historia, UNCPBA.

Petriella, Dionisio/Sosa Miatello, Sara (1976): Diccionario Biográfico Italo-Argentino. Buenos Aires: Asociación Dante Alighieri.

Piñeiro, Alberto (1994): "El radicalismo social moderno: 'Hechos e Ideas' (19351941)". En: Ansaldi, Waldo et al: Argentina en la paz de dos guerras. Buenos Aires: Editorial Biblos, pp. 295-315.

Ponce, Aníbal (1938): Cursos y Conferencias, XII, 11-12. Buenos Aires.

- (1958): Cuadernos de Cultura, 35, Buenos Aires.

- (1938): Humanismo burgués y Humanismo proletario. México: Editorial América.

- (1974): Obras completas, 4 tomos. Buenos Aires: Ed. Cartago

"Pour une meilleure connaissance de la diaspora juive italienne après les lois raciales de 1938" (perspectives de recherche) (mai 1999): La Trace. Cahiers du CEDEI, 11-12.

Racine-Furlaud, Nicole (1986): "Le Comité de vigilance des intellectuels antifascistes (1934-1939)". En: VV.AA.: La France en mouvement, 1934-1938, (Présentation Jean Bouvier). Champ Vallon, pp. 298-322.

- (1998): “L'Union Internationales d'ecrivains pendant l'entre-deux-guerres". En: Wolikow, Serge/Bleton-Ruget, Annie (sous la direction de), Antifascisme et nation. Les gauches européenes au temps du Front populaire, Dijón: Université de Bourgogne, pp. 31-47. 
Ramos, Jorge Abelardo (1957): Revolución y contarrevolución en Argentina, IV (El sexto dominio, 1922-1943). Buenos Aires: Plus Ultra.

Rapone, Leonardo (1999): Antifascismo e società italiana, 1926-1940. Milano. Edizioni Unicopli.

Ravignani, Emilio (1935): Hechos e Ideas. Revista Radical, I, 6.

Repetto, Nicolás (1957): Mi paso por la política (De Uriburu a Perón). Buenos Aires: Santiago Rueda Editor.

Salvemini, Gaetano (1935): "El capital y el trabajo en la Italia fascista". En: Hechos e Ideas. Revista Radical, I, 1, pp 349-354.

- (1936): "Puede Italia vivir dentro de sus fronteras". En: Hechos e Ideas. Revista Radical, I, 10, pp. 105-118.

- (1938): "La vida de Carlo y Nello Rosselli, víctimas del fascismo". En: Hechos e Ideas. Revista Radical, III, 28, pp. 219 y ss.

Santarelli, Enzo (1977): La revisione del marxismo in Italia. Milano: Feltrinelli.

Schenkolewski-Kroll, Silvia (1999): "El Partido Comunista en la Argentina ante Moscú: deberes y realidades, 1930-1941”. En: Estudios Interdisciplinarios de América Latina y el Caribe, 10, 2, pp. 91-107.

Schwartzstein, Dora (2001): Entre Franco y Perón. Barcelona: Crítica.

Sincero (1935): “La muerte se llama fascismo". En: Hechos e Ideas. Revista Radical, I, 5 , pp. 37 y ss.

Sigal, Silvia (1991): Intelectuales y poder en la década del 60. Buenos Aires: Punto Sur Editores.

Sirinelli, Jean-François (1996): Intellectuels et passion françaises. Manifestes et pétitions au $X x^{e}$ siècle. Paris: Gallimard.

Smolensky, Eleonora María/Jarach, Vera Vigevani (1998): Tante voci, una storia. Italiani ebrei in Argentina, 1948-1948, a cura di Iannettone, Giovanni. Bologna: Il Mulino. (Hay edición en español): Tantas voces, una historia. Italianos judios en la Argentina, 1938-1948. Buenos Aires: Temas Grupo Editorial.

Sturzo, Luigi (1937): “El Estado Totalitario”. En: Hechos e Ideas. Revista Radical, II, 19 , p. 364.

Terracini, Lore (1989): “Una inmigración muy particular: 1938, los universitarios italianos en la Argentina". En: Anuario del IEHS, IV, pp. 335-369.

Tobia, Bruno (1993): Scrivere contro. Ortodossi ed eretici nella stampa antifascista dell'esilio, 1926-1934. Roma: Bulzoni editore.

Trebitsch, Michel (1998): “Organisations internationales de cooperation intellectuelle dans l'entre-deux-guerres”. En Wolikow, Serge/Bleton-Ruget Annie (sous la direction de), Antifascisme et nation. Les gauches européenes au temps du Front populaire. Dijón: Université de Bourgogne, pp. 49-58.

Treves, Renato (1947): "Los estudios filosóficos en la Argentina en el último decenio". En: Cursos y Conferencias, XV, XXX, 179-80, pp. 372-377.

- (1957): "Eduardo Couture (1904-1956)", en: Rivista internazionale di filosofia del diritto, XXXIV, 3-4, pp. 468-473.

- (1990): "Una voce sulla diaspora intellettuale in Argentina", en: Sechi, Maria: Fascismo ed esilio, II. Pisa: Giardini. 
- (1990): Sociologia e socialismo. Ricordi e incontri. Milano: Franco Angeli.

Trifone, Víctor/Svarzman Gustavo (1993): La repercusión de la guerra civil española en la Argentina, 1936-1939. Buenos Aires: CEAL.

Tuntar, José (1939): "El antiguo imperialismo romano y el neo-imperialismo italiano: Cartago y Túnez". En: Cursos y Conferencias, VII, XIV, 12, pp. 1221-1234.

Weinstein, Marcos (1937): "El judaismo ante el pensamiento marxista contemporáneo". En: Judaica, IV, 45, pp. 77-79.

Weschler, Diana (2002): “Arte y política en la encrucijada de la internacional antifascista”. Ponencia presentada en: Segundas Jornadas UTDT de Historia. Política y Sociedad en Europa, siglos XIX y XX.

Winock, Michel (1999): Le siècle des intellectuels. Paris: Éditions du Seuil.

Wolikow, Serge/Bleton-Ruget, Annie (sous la direction de) (1998): Antifascisme et nation. Les gauches européenes au temps du Front populaire. Dijón: Université de Bourgogne, Editions Universitaires.

XIVe. Congrés International des P.E.N. Clubs, 5-15 septembre 1936 (1937): Discours et débats. Buenos Aires.

Zuleta, Emilia de (1999): Españoles en Argentina. El exilio literario de 1936. Buenos Aires: Ediciones Atril. 